\title{
Naloxone Breeding Effectiveness in Rat Suffering from Nitric Oxide-induced Polycystic Ovary Syndrome
}

\author{
${ }^{1}$ Manizheh Karami, ${ }^{2}$ Fatemeh Lakzaei, ${ }^{3}$ MohammadReza Jalali Nadoushan
}

\section{ABSTRACT}

Background and objective: Polycystic ovary syndrome (PCOS) can be induced in Wistar rats by over production of nitric oxide (NO). This study evaluated the efficacy of naloxone on the breeding characteristics of rats suffering from nitric oxide induced PCOS.

Materials and methods: Twenty-four female Wistar rats (200-250 gm) were kept as virgin under standard conditions. They were divided into four groups $(n=6)$. One group of the animals received L-arginine $(50 \mathrm{mg} / \mathrm{kg}$ ) intraperitoneally (i.p.) for 9 days/once a day. Another group was administered naloxone hydrochloride $(0.4 \mathrm{mg} / \mathrm{kg}$, i.p.) prior to injection of L-arginine. The third group was injected solely naloxone. Control group received saline solution $(1 \mathrm{ml} / \mathrm{kg}$, i.p.). After the treatments, all female rats were coupled with the intact males. They were then separated by observation of vaginal plaques; it was considered as day 0 of pregnancy. Eventually, they were operated on days 18 to 19 of the gestation to collect the animals' ovaries. The samples were studied for pathological evidence. The fetal number and weight along with the fetal crown-rump length $(\mathrm{CRL})$ were measured.

Results: The ovaries obtained from the L-arginine treated group had large cysts with thickened granulosa cell layer in contrast to those of the control or naloxone treated rats $(p<0.0001)$. The number of fetus though showed a decrease in the L-arginine treated rats $(3 \pm 1)$, but the fetal weight or fetal $C R L$ did not change $(p>0.05)$.

Conclusion: This study may clearly illustrate the polycystic characteristics in the L-arginine treated group. It may particularly display the breeding efficacy of naloxone in rats with PCOS.

Keywords: Breeding, L-Arginine, Naloxone, Nitric oxide, PCOS, Rat.

How to cite this article: Karami M, Lakzaei F, Nadoushan MRJ. Naloxone Breeding Effectiveness in Rat Suffering from Nitric Oxide-induced Polycystic Ovary Syndrome. Int J Infertil Fetal Med 2015;6(2):67-72.

Source of support: Nil

Conflict of interest: None

Date of received: $20-06-15$

${ }^{1}$ Faculty Staff-Associate Professor, ${ }^{2} \mathrm{MSc}$ Student, ${ }^{3}$ Professor

1,2Department of Biology, Shahed University, Tehran, Iran

${ }^{3}$ Department of Pathology, Shahed University, Tehran, Iran

Corresponding Author: Manizheh Karami, Faculty StaffAssociate Professor, Department of Biology, Shahed University, Tehran, Iran, Phone: 982151212243, e-mail: karami@shahed.ac.ir
Date of acceptance: 28-06-15

Date of publication: August 2015

\section{INTRODUCTION}

About 11 to $15 \%$ of women in reproductive age suffer from polycystic ovary syndrome (PCOS). This syndrome is associated with several symptoms, such as irregular menstruation, amenorrhea, ovulation-related infertility, polycystic ovaries and hyperandrogenism. ${ }^{1}$ Other signs of the disorder are hyperinsulinemia, glucose intolerance, abnormal blood lipid levels, obesity, ${ }^{2}$ and insulin resistance. ${ }^{3}$ The insulin resistance is linked with impaired production/release of endothelium-derived nitric oxide (NO). ${ }^{4}$ The NO, a paracrine messenger, participates in several physiological and pathophysiological events in the endocrine organs. This small, diffusible, lipophilic free-radical gas is produced from the oxidation of terminal guanidino nitrogen of arginine by the action of nitric oxide synthase (NOS) enzyme. ${ }^{5,6}$ The local inflammatory generator NO mediates significant and diverse signaling functions nearly in every organ system; it is involved in the induction of the PCOS, a disorder which is alleviated by anti-inflammatory naloxone. ${ }^{6-9}$ This famous opioid antagonist has been previously described may have reinforcing effect and abuse liability under conditions. ${ }^{10}$ The drug naloxone clearly affects the NOS activity in the brain areas of Wistar rats. ${ }^{11}$ This narcotic drug when using collectively with L-arginine, the NO precursor, shows a beneficial effect on the PCOS' signs. ${ }^{8}$ The drug, therefore, may have the potential to affect the symptoms of the PCOS disorder; a hypothesis needs to be clarified.

This work treated the female Wistar rats by naloxone jointly with L-arginine to signify the NO involvement in the PCOS. We evaluated the effectiveness of naloxone on the breeding quality of rats suffering from NO-induced PCOS. We planned to show the improvement effect of naloxone on the breeding values as well. Beside the evaluation of the breeding quality of naloxone, the blood samples of the animals were analyzed for the cardiometabolic outcomes.

\section{MATERIALS AND METHODS}

\section{Animals}

In this experimental study, 24 females Wistar rats (weighing 200-250 gm, purchased from Pasteur Institute of Iran) 
were retained under standard conditions in accordance to the guides for the care and use of laboratory animals. ${ }^{12}$ The animals were kept under proper temperature $(21 \pm$ $3^{\circ} \mathrm{C}$ ) and 12-hour light/dark cycle with food and water ad libitum. All experiments were approved by the local ethical committee at Shahed University (Document No: 554/169264/9202).

\section{Female Cycle Test}

Female rats with 4 to 5 days sexual cycle are always in diestrous ${ }^{13,14}$ unless they mated with the males. Thus, the rats kept virgin and did not expose to the males, were chosen for studying. Furthermore, the animals' vaginal smears were examined by Papanicolaou smear test during the entire experiment and determined as diestrous.

\section{Experimental Procedure}

The drugs were L-arginine (Merck co., Germany), naloxone hydrochloride (Tolid Daru Co., Tehran), ketamine and xylazine (Veterinary Organization, Iran). The drugs were administered under the following program:

The animals were randomly divided into four groups ( $\mathrm{n}=6$ per group); one group of them received single L-arginine (50 mg/ $\mathrm{kg}$, i.p., 9 days/once daily), and another group was injected naloxone $(0.4 \mathrm{mg} / \mathrm{kg}$, i.p.), and the third group was administered naloxone 30 minutes prior to the L-arginine. The control group exclusively received saline solution $(1 \mathrm{ml} / \mathrm{kg}$, i.p.). Drug doses and duration of study periods accorded with our previous experiences. The treated rats were coupled with the intact males 'Coupling of rats' by ending of drug administration procedure. Following observation of vaginal plaques and subsequently to the smear test, they were isolated and graded day 0 of pregnancy. They eventually passed surgery on days 18 to 19 of gestation; midline incisions in the rats' lower abdomen areas were performed to expose the reproductive organs. The control and the experimental rats' ovaries' dimensions were exactly scaled with Collis under binocular objectives. The ovaries samples were then dissected out and collected in $10 \%$ formalin for histological analysis. The fetuses were additionally carefully examined to provide the necessary data. The fetal number and weight, and the fetal crown-rump length (CRL) were measured. For histological investigations, the fixed samples provided in $10 \%$ formalin were processed with tissue processor through paraffin embedding. The serially sections $(3-4 \mu \mathrm{m})$ were prepared and stained by means of hematoxylin and eosin (H\&E) method. ${ }^{15}$ After the dehydration the sections were eventually mounted with entellan (Merck Co., Germany). The prepared slides were evaluated by light photomicroscope (Olympus) at 4 to $40 \times$. The photos provided by photomicroscope (Olympus) were assessed in $100-\mu \mathrm{m}^{2}$ units under magnifi- cation 4 to $40 \times$ using an Image Tool program (UTHSCSA, version 2.03, USA), the free image processing and analysis program for Microsoft Windows to provide quantification for $100 \mu \mathrm{m}^{2}$ units. The differences between experimental and control unit level were obtained using t-test analysis.

\section{Blood Parameter Assay}

Up to 24 hours after the completion of the experiments, the rats were anesthetized by intraperitoneally (i.p.) injection of ketamine $(100 \mathrm{mg} / \mathrm{kg})$ and xylazine $(20 \mathrm{mg} / \mathrm{kg})$. With ethical consideration, the rats' heart blood samples were collected to assess the sera parameter profile. The samples were kept under room temperature for at least 30 minutes; they were then centrifuged at 3000 to $5000 \mathrm{gm}$ for 15 minutes. The level of low-density lipoprotein (LDL) was measured based on competition binding using the enzyme-linked immunosorbent assay (ELISA) and read by an ELISA reader.

\section{Statistical Analysis}

Initially, the data were evaluated by Kolmogorov-Smirnov $(\mathrm{K}-\mathrm{S})$ to determine a normal distribution. The analysis of variance (ANOVA) was performed using statistical package for the social sciences (SPSS) software (version 13.0; SPSS, Inc., Chicago, IL). Tukey-Kramer's Post hoc test was used to calculate differences between groups. Statistical significance was considered at $\mathrm{p}<0.05$. All data are expressed as mean \pm SEM.

\section{RESULTS}

\section{Female Cycle}

The female sexual cycle phase of rats was indicated as diestrous. In this phase, the cell type abundant in the smears were the round nucleated epithelial cells.

\section{Histology}

The ovaries of control rats treated with saline had mature follicles (Fig. 1A). The ovaries collected from the L-arginine treated group (50 mg/kg) exhibited large cysts with thickened granulosa cell layer or large cystic follicles with scant granulosa cells (Fig. 1B). However, the samples of rats administered naloxone $(0.4 \mathrm{mg} / \mathrm{kg})$ prior to the L-arginine $(50 \mathrm{mg} / \mathrm{kg})$, illustrated significant $(\mathrm{t}=3.656$, sig $(2$-tailed $)=0.004$ ) attenuation of cysts (Fig. 1C). This group, moreover, exhibited mature follicular appearance in contrast to the solely L-arginine group. Also, the single naloxone group had mature follicles (Fig. 1D).

The quantified results for the images analyses are presented $(\mathrm{F}=23.629, \mathrm{p}<0.0001)$. 


\section{Breeding Values (Fetal Number, and Fetal Crown-Rump Length, and Fetal Weight)}

Number of fetus was calculated in all groups and found that there was a significant difference between the $\mathrm{L}$-arginine group and all of the others groups $\left(\mathrm{F}_{3,20}=\right.$ 4.042, $\mathrm{p}=0.022$ ) (Fig. 2). This breeding value in group treated L-arginine was less than the other groups.

Crown-rump length of fetus was determined for further evaluation of breeding characteristic in the rats. This parameter had no difference ( $\mathrm{p}>0.05$ ) in the groups (Fig. 3).

Weight of fetus was indicated for further calculation of breeding feature in the rats. The weights of the fetuses was not changed ( $p>0.05)$ in the groups (Fig. 4).

\section{Serum Agent Levels}

The analysis of data for LDL serum level indicates a significant change $\left(\mathrm{F}_{3,20}=6.523, \mathrm{p}=0.003\right)$ which is shown in Figure 5.

\section{DISCUSSION}

This research plan was designed to indicate the naloxone effect on polycystic changes induced by L-arginine in

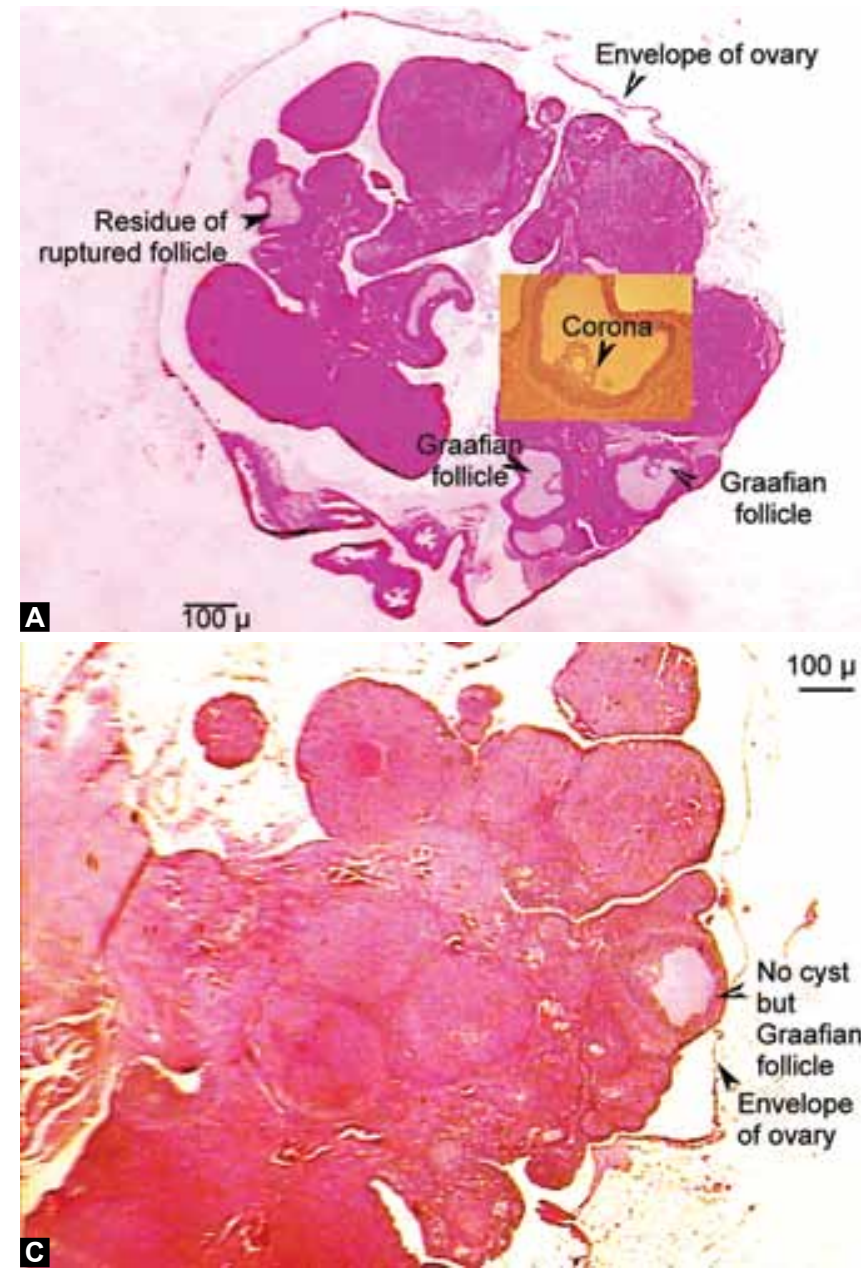

the ovary. We aimed to indicate associated reductions in breeding efficiency.

Present study concisely demonstrated the following findings: fall in number of fetus $(3 \pm 1)$ in the L-arginine treated Wistar rats along with the presence of the large cyst formation in the rats' ovaries (Fig. 1B) and a high level of LDL (Fig. 5) as a main metabolic outcome of PCOS.

To discuss about the high numbers of cysts in the L-arginine treated samples the present study may properly suggest a role for free-radical NO in the breeding events. The NO which is formed by L-arginine in the presence of NO synthase (NOS), ${ }^{5}$ as an important paracrine messenger, participates in endocrine physiological and pathophysiological events. ${ }^{5}$ This local inflammatory generator ${ }^{7}$ as previously been shown by other researchers mediates the ovulatory process and regulates the function of corpus luteum. ${ }^{16-19}$ We may additionally introduce a functional role for the molecule in the follicular events in view of the fact that the polycystic aspect in this study was observed in treated rats' ovaries receiving the continual usage of the L-arginine. Moreover, the present findings may confirm our previous study ${ }^{8}$ that demonstrated the hyperactivity of enzyme NOS after

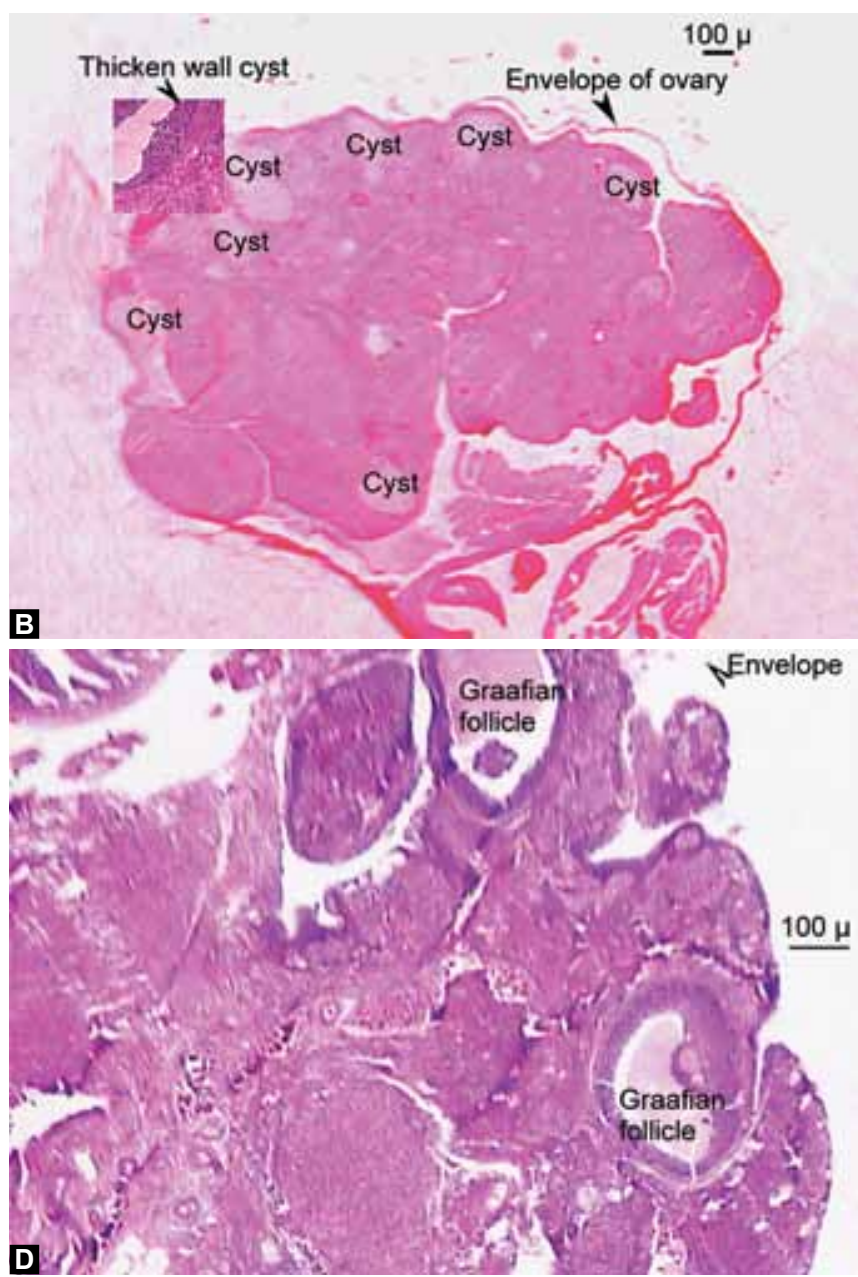

Figs 1A to D: Panels show the ovaries of four groups of rats: control (A) single L-arginine, (B) naloxone plus L-arginine (C) and naloxone alone (D). Bars beside the samples show the $\mathrm{mm}$ values. The arrows and notes in each picture signify the desired characteristics 


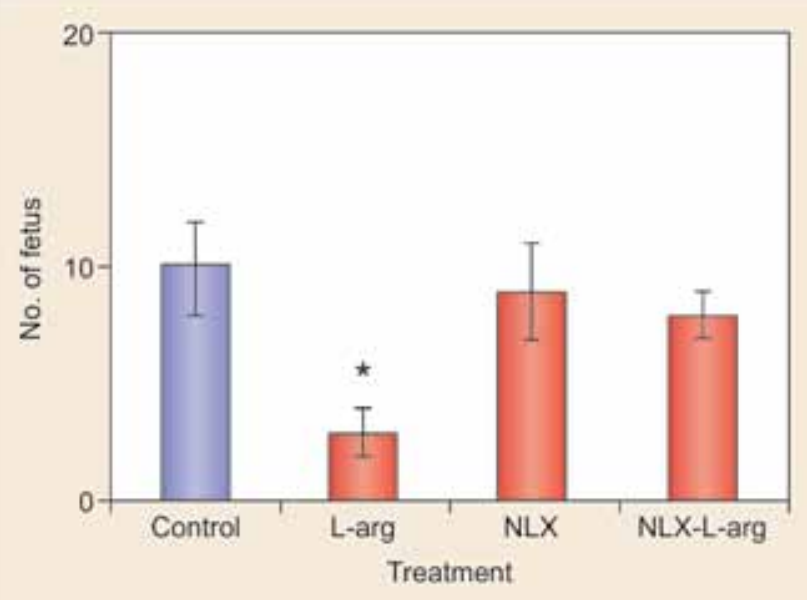

Fig. 2: Figure indicates the number of fetus in rats. X-axis denotes the control and the experimental groups. Control group was saline injected $(1 \mathrm{ml} / \mathrm{kg}$, i.p., 9 days/once per day). The experimental groups were single L-arginine (L-Arg: $50 \mathrm{mg} / \mathrm{kg}$, i.p., 9 days) or single naloxone (NLX: $0.4 \mathrm{mg} / \mathrm{kg}$, i.p., 9 days) or L-arginine (50 mg/kg, i.p., 9 days) plus naloxone $(0.4 \mathrm{mg} / \mathrm{kg}$, i.p., 9 days) recipients. Naloxone was injected 30 minutes prior to L-arginine in the naloxone plus L-arginine group, values are written as mean \pm SEM. ${ }^{*} p<0.05$ vs control (Tukey Post hoc test)

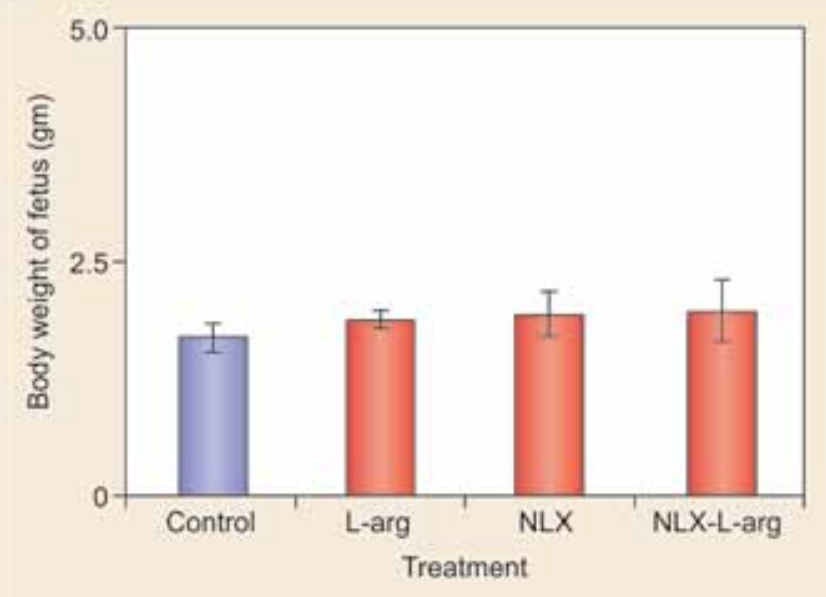

Fig. 4: The fetal weight. X-axis denotes the control and experimental groups. Control group was only injected saline $(1 \mathrm{ml} / \mathrm{kg}$, i.p., 9 days/once per day). The experimental rats were recipients of single L-arginine (L-Arg: $50 \mathrm{mg} / \mathrm{kg}$, i.p., 9 days) or single naloxone (NLX: $0.4 \mathrm{mg} / \mathrm{kg}$, i.p., 9 days) or L-arginine $(50 \mathrm{mg} / \mathrm{kg}$, i.p., 9 days) plus naloxone $(0.4 \mathrm{mg} / \mathrm{kg}$, i.p., 9 days). In the naloxone-L-arginine group, the naloxone was injected 30 minutes prior to the L-arginine. Values are presented as mean \pm SEM

repeated injections of L-arginine. In accord, it has recently been indicated that the guanidino-substituted analog of L-arginine known as asymmetrical dimethylarginine $(\mathrm{ADMA})^{20,21}$ mediates the adverse vascular effects. Thus, the findings of present plan may properly appear the risk profile of PCOS. Considering that the ADMA is elevated in patients with $\mathrm{PCOS},{ }^{22}$ the achievement can be similarly implied for the L-arginine over usage.

The polycystic feature along with a decreased breeding aspect (Fig. 2) and increased LDL level (Fig. 5) may

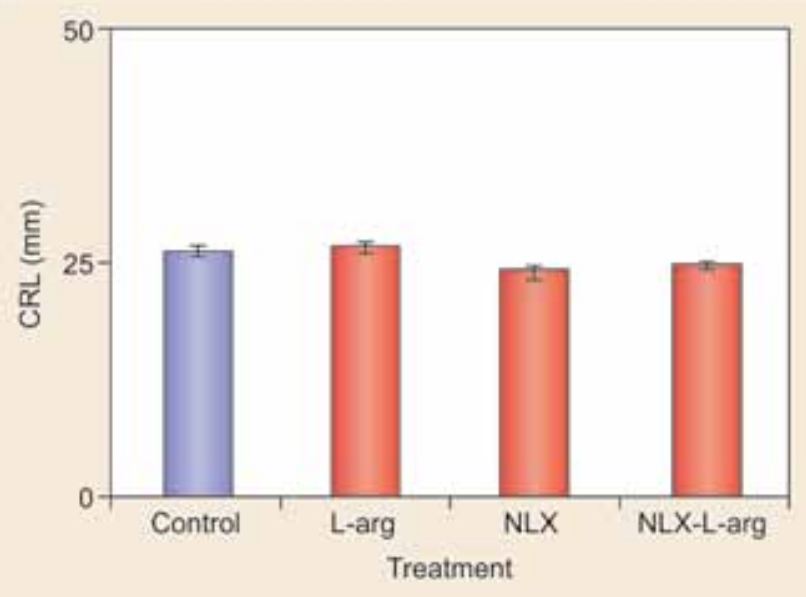

Fig. 3: Figure indicates the crown-rump length $(C R L)$ of fetus. $\mathrm{X}$-axis denotes the control and the experimental groups. Control rats were solely injected saline $(1 \mathrm{ml} / \mathrm{kg}$, i.p., 9 days/once per day). Other rats received single L-arginine (L-Arg: $50 \mathrm{mg} / \mathrm{kg}$, i.p., 9 days) or single naloxone (NLX: $0.4 \mathrm{mg} / \mathrm{kg}$, i.p., 9 days) or L-arginine (50 $\mathrm{mg} / \mathrm{kg}$, i.p., 9 days) collectively with naloxone $(0.4 \mathrm{mg} / \mathrm{kg}$, i.p., 9 days). Naloxone was injected 30 minutes prior to L-arginine (50 $\mathrm{mg} / \mathrm{kg}$ ). Values are given as mean \pm SEM

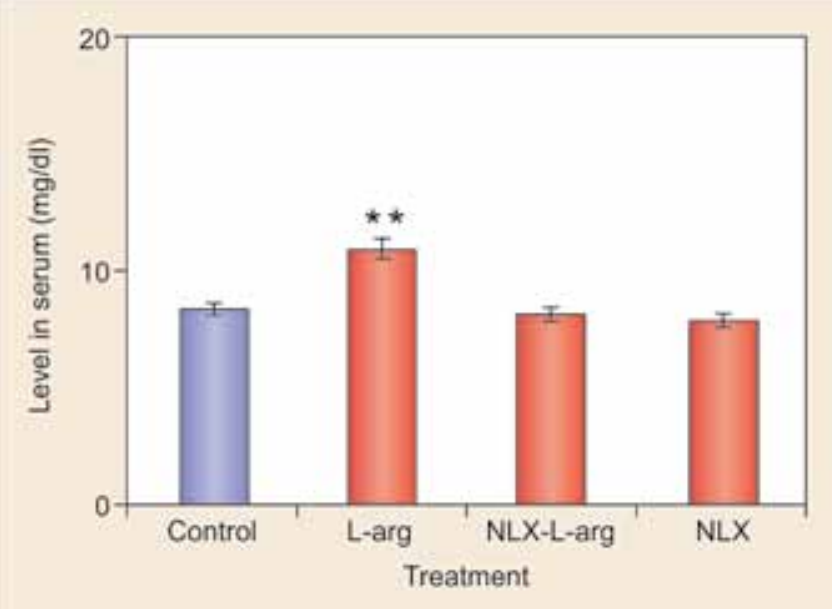

Fig. 5: This figure illustrates the numbers of fetuses both in the control and experimental groups. Control rats were injected saline ( $1 \mathrm{ml} / \mathrm{kg}$, i.p., 9 days/once per day). The experimental groups were administered single L-arginine (L-Arg: $50 \mathrm{mg} / \mathrm{kg}$, i.p., 9 days), single naloxone (NLX: $0.4 \mathrm{mg} / \mathrm{kg}$, i.p., 9 days), L-arginine (50 mg/kg, i.p., 9 days) plus naloxone $(0.4 \mathrm{mg} / \mathrm{kg}$, i.p., 9 days). Naloxone was injected prior (30 $\mathrm{min}$ ) to the L-arginine in the later. Values are indicated as mean \pm SEM. ${ }^{* *} p<0.01$ vs control (Tukey Post hoc test)

redirect us to the PCOS. But other signs of the syndrome, such as the hyperandrogenism and hyperinsulinemia did not emerge in this model. So, we may involve the mentioned above metabolic factors in the pathophysiology of the disorder. In view that the production of large cysts due to treatment by NO producer, L-arginine, was significantly reduced in the L-arginine plus naloxone recipients, we notify that the drug may possess various pharmaceutical properties to suppress the low-grade inflammatory disease PCOS. ${ }^{23}$ 
For discussion of the breeding values, we may affirm that despite of insignificant change in fetal weight or CRL (Figs 3 and 4) the number of the fetus in the L-arginine treated mothers was low when compared with the control and naloxone groups (Fig. 2). Regarding the findings, we may introduce the proinflammatory $\mathrm{NO}$ as a cause of infertility. The NO may activate inflammatory processes in the ovary to produce this effect. However, the anti-inflammatory naloxone reversed the decline in fertility probably by affecting the endocrine and metabolic parameters related to the PCOS. To explain the metabolic effect, we give notice that the naltrexone reduces the food intake in cases with android obesity, hyperinsulinemia, insulin-resistance. ${ }^{24}$ Such metabolic abnormalities have also been reported previously due to a link between opioids and PCOS-related insulin response to glucose load. ${ }^{25,26}$ Similar abnormalities have been additionally indicated in the animal model PCOS. ${ }^{27-29}$ This study may further show the NO overproduction as harmful for Wistar rat reproduction. The NO as a shortlived cytotoxic mediator has been related to the atresia of follicles. ${ }^{30}$ Also, in view of our result the inflammatory processes have crucial role in reproduction at all levels from the follicles and ovarian function to the accessory sex organs (i.e. uterus).

We, furthermore, expected to involve the NO in fetal weight loss or deformity of the fetus. However, the NO production caused insignificant change in the parameters. By reviewing of previous data, the NOergic neurons of the pelvic plexus ${ }^{31}$ involve in uterine smooth muscle change via NOergic terminals. ${ }^{32}$ Based on our results, a more complex mechanism may normalize the fetal development in the uterine cavity. Because despite the main effect of $\mathrm{NO}$ on the breeding rate, we did not show the noticeable change in the developmental parameters.

In conclusion, we demonstrated the involvement of inflammatory agents in reproductivity of Wistar rats. The NO-induced infertility was improved with an antiinflammatory opiate antagonist, naloxone. We evidenced that the fetal development is less sensitive to the inflammatory events. Available trials are now scarce, and we recommend for future research and clinical work.

\section{ACKNOWLEDGMENTS}

This study was supported financially by Research deputy of Shahed University. The authors express gratitude to MS Fatemeh Hassani for expert assistance in histology procedure.

\section{REFERENCES}

1. Speroff L, Fritz M. Clinical gynecologic endocrinology and infertility. 7th ed. New York: Lippincott Williams and Wilkins; 2005. p. 485-513.
2. Dokras A, Bochner M, Hollinrake E, MarkhamS, Vanvoorhis B, Jagasia DH. Screening women with polycystic ovarian syndrome for metabolic syndrome. Obstet Gynecol 2005; 106(1): 131-137.

3. Apridonidze T, Essah PA, Iuorno MJ, Nestler JE. Prevalence and characteristics of the metabolic syndrome in women with polycystic ovary syndrome. J Clin Endocrinol Metab 2005;90(4):1929-1935.

4. Nácul AP, Andrade CD, Schwarz P, de Bittencourt Pl Jr, Spritzer PM. Nitric oxide and fibrinogen in polycystic ovary syndrome: Associations with insulin resistance and obesity. Eur J Obstet Gynecol Reprod Biol 2007 Aug;133(2):191-196.

5. Zackrisson U, Mikuni M, Wallin A, Delbro D, Hedin L, Brännström M. Cell-specific localization of nitric oxide synthases (NOS) in the rat ovary during follicular development, ovulation and luteal formation. Hum Reprod 1996; 11(12):2667-2673.

6. Dudzinski DM, Igarashi J, Greif D, Michel T. The regulation and pharmacology of endothelial nitric oxide synthase. Annu Rev Pharmacol Toxicol 2006;46:235-276.

7. Nakamura Y, Kashida S, Nakata M, Takiguchi S, Yamagata Y, Takayama H. Changes in nitric oxide synthase activity in the ovary of gonadotropin treated rats: the role of nitric oxide during ovulation. Endocrin J 1999;46(4):529-538.

8. Hassani F, Karami M, Jalali Nadoushan MR, Eftekhari Yazdi P. Nitric oxide-induced polycystic ovaries in the Wistar rat. Int J Fertil Steril 2012;6(2):111-116.

9. Liu SL, Li YH, Shi GY, Chen YH, Huang CW, Hong JS, et al. A novel inhibitory effect of naloxone on macrophage activation and atherosclerosis formation in mice. J Am Coll Cardiol 2006; 48(9):1871-1879.

10. Comer SD, Collins ED. Self-administration of intravenous buprenorphine and the buprenorphine/naloxone combination by recently detoxified heroin abusers. J Pharmacol Exp Ther 2002 Nov;303(2):695-703.

11. Bhat GK, Mahesh VB, Ping L, Chorich L, Wiedmeier VT, Brann DW. Opioid-glutamate-nitric oxide connection in the regulation of luteinizing hormone secretion in the rat. Endocrinology 1998;139(3):955-960.

12. Baravalle C, Salvetti NR, Mira GA, Pezzone N, Ortega HH. Microscopic characterization of follicular structures in letrozole-induced polycystic ovarian syndrome in the rat. Arch Med Res 2006;37(7):830-839.

13. Maeda KI, Kura SO, Tsukamura H. Physiology of reproduction, in the laboratory rat: the handbook of experimental animal. Hrinke CJ, editor. London: Academic press; 2000. p. 145-176.

14. MohammadzadehA,HeidariM,Soltan GhoraiiH,Zarnani AH. Induction of endometriosis by implantation of endometrial fragments in female rats. Iran J Reprod Med 2006;4(2):63-67.

15. Manneras L, Cajander S, Holmang A, Seleskovic Z, Lystig T, Lonn $\mathrm{M}$, et al. A new rat model exhibiting both ovarian and metabolic characteristics of polycystic ovary syndrome. Endocrinology 2007;148(8):3781-3791.

16. Shukovski L, Tsafhn A. The involvement of nitric oxide in the ovulatory process in the rat. Endocrinology 1994;135(5): 2287-2290.

17. Van Voorhuis BJ, Dunn MS, Snyder GD, Werner CP. Nitric oxide: an autocrine regulator of human granulosa-luteal cell steroidogenesis. Endocrinology 1994;135(5):1799-1806.

18. Powers RW, Chen L, Russell PT, Larsen WJ. Gonadotropin stimulated regulation of blood-follicle barrier is mediated by nitric oxide. Am J Physiol 1995;269(2 Pt 1):E29O-E298. 
19. Bonello N, McKie K, Jasper M. Inhibition of nitric oxide effects on IL-lb-enhanced ovulation rate, steroid hormones, and ovarian leukocyte distribution at ovulation in the rat. Biol Reprod 1996;54(2):436-445.

20. Yildizhan R, Ilhan GA, Yildizhan B, Kolusari A, Adali E, Bugdayci G. Serum retinol-binding protein 4, leptin, and plasma asymmetric dimethylarginine levels in obese and non obese young women with polycystic ovary syndrome. Fertil Steril 2011;96(1):246-250.

21. Landim MBP, Casella Filho A, Chagas ACP. Asymmetric dimethylarginine (ADMA) and endothelial dysfunction: implications for atherogenesis. Clinics (Sao Paulo) 2009;64(5): 471-478.

22. Heutling D, Schulz H, Nickel I, Kleinstein J, Kaltwasser P, Westphal S, et al. Asymmetrical imethylarginine, inflammatory and metabolic parameters in women with polycystic ovary syndrome before and after metformin treatment. J Clin Endocrinol Metab 2008;93(1):82-90.

23. Karimzadeh L, Nabiuni M1, Kouchesfehani HM, Adham H, Bagheri A. Effect of bee venom on IL-6, COX-2 and VEGF levels in polycystic ovarian syndrome induced in Wistar rats by estradiol valerate. J Venom Anim Toxins Incl Trop Dis 2013;19(1):19-32.

24. Fruzzetti F, Bersi C, Parrini D, Ricci C, Genazzani AR. Effect of long-term naltrexone treatment on endocrine profile, clinical features, and insulin sensitivity in obese women with polycystic ovary syndrome. Fertil Steril 2002;77(5):936-944.

25. Guido M, Romualdi D, Lanzone A. Role of opioid antagonists in the treatment of women with glucoregulation abnormalities. Curr Pharm Des 2006;12(8):1001-1012.
26. Guido M, Pavone V, Ciampelli M, Murgia F, Fulghesu AM, Apa R, et al. Involvement of ovarian steroids in the opioid mediated reduction of insulin secretion in hyperinsulinemic patients with polycystic ovary syndrome. J Clin Endocrinol Metab 1998;83(5):1742-1745.

27. Mahesh VB, Mills TM, Bagnell CA, Conway BA. Animal models for study of polycystic ovaries and ovarian atresia. In: Dhindsa DS, Anderson E, Kalra SP, editors. Regulation of ovarian and testicular function. New York: Plenum; 1987. p. 237-258.

28. Hamilton SA, Garverick HA, Keisler DH, Xu ZZ, Loos K, Youngquist RS, et al. Characterization of ovarian follicular cysts and associated endocrine profiles in dairy cows. Biol Reprod 1995;53(4):890-898.

29. Salvetti NR, Canal AM, Gimeno EJ, Ortega HH. Polycystic ovarian syndrome: temporal characterization of the induction and reversion process in an experimental model. Braz J Vet Res Anim Sci 2004 Nov-Dec;41(6):389-395.

30. Drapier JC, Wietzerbin J, Hibbs JB Jr. Interferon- $\gamma$ and tumor necrosis factor induce the l-arginine-dependent cytotoxic effector mechanism in murine macrophages. Eur J Immunol 1988;18(10):1587-1592.

31. Burnett AL, Lowenstein CJ, Bredt DS, Chang TS, Snyder SH. Nitric oxide: a physiologic mediator of penile erection. Science 1992 Jul 17;257(5068):401-403.

32. Brännström M, Janson PO. The role of leukocytes and cytokines as paracrine regulators in the mechanisms of ovulation. In: Fujimoto S, Hsueh AJW, Strauss IH, editors. Frontiers in Endocrinology. New York: Ares-Serono Symposium Pub; 1995;13. p. 225-233. 